\title{
Place of Non Contrast Thin-Slice Spiral Computed Tomography in Evaluation of Stone-Free Ratio after Percutaneous Nephrolithotomy
}

\author{
Bayram Guner $^{\mathrm{a}} \quad$ Cenk Gurbuz $^{\mathrm{b}} \quad$ Lutfi Canat $^{\mathrm{b}} \quad$ Turhan Caskurlu $^{\mathrm{b}}$ \\ aDepartment of Urology, Mus State Hospital, Mus; 'bepartment of Urology, Medeniyet University, Istanbul, Turkey
}

\author{
Key Words \\ Computed tomography $\cdot$ Fluoroscopy $\cdot$ Kidney stone • \\ Percutaneous nephrolithtomy
}

\begin{abstract}
Purpose: To search the place of non contrast abdominal computed tomography to detect the stone-free rate after percutaneous nephrolithotomy (PNL) and the clinical importance of its superiority against to plain film radiography (KUB). $\mathbf{M a}$ terials and Methods: Between February 2006 and July 2010, 62 patients including 27 women had no stone detected peroperative fluoroscopy and nephroscopy during PNL were included. Patients whom stone was not detected under 5 $\mathrm{mm}$ section upper abdomen non contrast spiral CT and KUB control in postoperative day 3 were defined as Group 1; patients whom stone was detected in a single slice CT were defined as clinically insignificant fragment (CIF)(Group 2) and patients whom stone was detected at least in two slice were defined as rest fragment (Group 3). Results: Median stone size were $22.3 \mathrm{~mm}$ (19-37 mm). Preoperative stone localization of groups were upper calyx, middle calyx, pelvis, lower calyx and 2.1, 14.9, 25.5 and $57.4 \%$, respectively. CIF was detected in postoperative CT control of 12 (25.5\%) patients whom stone was not followed in KUB and rest fragment was detected in $6(12.8 \%)$ patients. Three of patients whom rest fragment was detected required an additional intervention for stone. Conclusion: KUB which is routinely used to determine stone-free ratio after PNL operation is not sufficient to detect rest calculi and/or CIF existence in $38.3 \%$ patients. But when it is considered that most of rest stones detected
\end{abstract}

\section{KARGER}

Fax +4161306 1234

E-Mail karger@karger.ch

www.karger.com
(C) 2012 S. Karger AG, Basel

1015-9770/12/0062-0071\$26.00/0

Accessible online at:

www.karger.com/cur were CIF and only 6.3\% patients had additional intervention required rest calculi. We can think that CT follow-up is not absolutely required.

Copyright @ 2012 S. Karger AG, Basel

\section{Introduction}

Percutaneous nephrolithotomy (PNL) is an effective, minimally invasive procedure used for the treatment of large or complex renal calculi [1]. Residual fragments can be seen after PNL, which are most frequently present in the lower calyx group. Postoperative radiological evaluation for residual calculi is performed with different imaging techniques. The EAU Working Group Panel recommends that the selection of a stone-removing procedure should be based on the findings of a good-quality kidney-urine-bladder (KUB) graphy and computed tomography $(\mathrm{CT})$ examination is necessary only for uric acid stones. CT is better than a standard plain abdominal film of KUB, which detects all small residual fragments. In literature, definition of residual fragment and cut off value are very different and imaging methods to detect residual fragments are very diverse, such as KUB, CT, flexible nephroureteroscopy, second look procedure etc. The clinical problem is related to the risk of developing 
new stones from such nidi and stone related events with asymptomatic stone residuals. We searched the place of non contrast abdominal $\mathrm{CT}$ to detect the stone-free rate after PNL and the clinical importance of its superiority against to KUB.

\section{Materials and Methods}

From March 2009 to July 2010, we had 62 PNL cases in our centers and 11 of them were removed from the study due to rest calculus in postoperative scope and endoscopic inspection (Xray). Four patients were removed from the study because they had asked to continue their postoperative follow-up in another center. Inclusion criteria were observing no residual fragment on postoperative KUB after PNL. Fifty-one patients (53 renal units) undergoing PNL were included to study. Calculus that is bigger than $20 \mathrm{~mm}$ in kidney and the presence of kidney stones in the range of 10-20 $\mathrm{mm}$ that are non-responsive to extracorporeal shock wave lithotripsy were the PNL indications. CT and KUB were performed to all of the patients preoperatively and all of stones were radioopaque on KUB. PNL was performed to all of patients by 2 surgeons with amplatz dilatation set. All procedures were performed by urologist with high resolution Integra V5000 Carm (Phillips, Andover, Massachusetts, USA) in operation room. There are 27 male, 20 female patients in the study. Median age is 41.2 years (range 24-68 years). Six patients had multiple stones. Median stone size is $22.3 \mathrm{~mm}$ (range $19-37 \mathrm{~mm}$ ). Overall operation time is 72 minutes (range 50-112 minutes). Multiple percutaneous accesses were applied in 5 patients. Preoperatively, stones were localized in upper calyx $(2.1 \%)$, middle calyx $(14.9 \%)$, pelvis $(25.5 \%)$ and lower calyx $(57.4 \%)$ respectively. Stone-free was determined with 2 surgeons based on scanning endoscopic rigid nephroscopy and simultaneous scope. Patients who had no residual calculus in both methods were included to the study. In this case, KUB and CT were performed on the 3rd day postoperatively and the results were categorized as stone-free (Group I), fragments smaller than $5 \mathrm{~mm}$ in the largest single dimension (clinical insignificant fragment, CIF) (Group II), fragments $5 \mathrm{~mm}$ and greater (residual fragment) (Group III) respectively. KUB was negative in all of groups. Negative postprocedure KUB was confirmed by intraprocedural endoscopy. Presences of colic and concomitant hydronephrosis that are not responsive to symptomatic treatment were interference indications during postoperative period. Interference treatment was performed to 3 patients on the 17 th, 22nd and 29th days. One patient had no stone analysis. Flexible nephroscopy was not used in all of the patients. Exclusion criteria were presence of non opaque calculi and the finding of residual fragment on postoperative imaging $(n=11)(\mathrm{KUB})$ or intraoperative endoscopic inspection (rigid nephroscopy). Stone size was defined with the longest diameter of biggest stone on KUB or CT. In this study, noncontrast 64-slice Toshiba multislice Aquilion system (Toshiba Medical Systems, Tokyo, Japan) CT was performed using a 5-mm slice multidetector scanner. Patients were typically followed monthly postoperatively. High fluid intake and avoiding excessive intake of salt and animal protein were advised to all of the patients. All of patients were followed by history, physical examination, serum chemistry studies and urine culture when clinically indicated. Additional imaging method was not performed if it is not indicated postoperatively. Median follow-up was 3.4 months (range 3-5.7 months). Statistical analysis was performed by NCSS 2007 package program. Independent $t$ test and chi-square test were used to compare groups. Statistical significance was set as $\mathrm{p}<0.05$.

\section{Results}

In $25.5,12.8$ and $61.7 \%$ of patients who underwent postoperative CT control, CIF, residual fragment and no stone were detected respectively. None of the Group I and II required additional treatment follow-up. Extracorporeal shock wave lithotripsy, double J stent and ureteroscopy were applied $50 \%(n=3)$ of Group III on follow-up respectively (table 1). The other patients of Group III did not require intervention. There was no correlation between stone-free rate and multiple accesses $(\mathrm{p}<0.06)$. There is no statistically significant difference in groups on account of gender, stone localization, stone analysis result, age, duration of operation, stone size, BMI and CIF, residual fragment, stone free ratio (table 2, 3). Determination of sensitivity could not be performed statistically significant for KUB, because KUB was negative all of patients.

\section{Discussion}

Historically the goal of PNL has been complete stone removal. The presence of any residual calculi usually indicated failure of the procedure [2]. Multiple factors determine the success rates of urological stone procedure such as stone size, composition, used imaging methods, location (lower pole) and other anatomical parameters [3]. The residual stone burden can result with significant morbidity and may result in risk of additional anesthesia and the potential morbidity of a second (or third) operation [4]. KUB is the primary method of radiographic follow-up in patients undergoing PNL. However the KUB has low sensitivity than CT for smaller calculi $[5,6]$. So sometimes it requires complex postoperative imaging to avoid unnecessary additional procedures but detection of residual fragment and its benefits are controversial and can increase cost.

Endoscopic surveillance and CT are equally sensitive for detecting residual stones. Although CT is less expensive and avoids unnecessary endoscopic procedures in $20 \%$ of patients in adults, Osman et al. [7] compared KUB and ultrasound findings against the results of CT in 
Table 1. Group characteristics

\begin{tabular}{|c|c|c|c|c|}
\hline & Stone-free & Residual fragment & CIF & $\mathrm{p}$ \\
\hline Gender & & & & 0.361 \\
\hline Male & $\mathrm{n}=15(51.70 \%)$ & $\mathrm{n}=5(83.30 \%)$ & $\mathrm{n}=7(58.30 \%)$ & \\
\hline Female & $\mathrm{n}=14(48.30 \%)$ & $\mathrm{n}=1(16.70 \%)$ & $\mathrm{n}=5(41.70 \%)$ & \\
\hline Stone localization & & & & 0.716 \\
\hline Lower calyx & $\mathrm{n}=16(55.20 \%)$ & $\mathrm{n}=3(50.00 \%)$ & $\mathrm{n}=8(66.70 \%)$ & \\
\hline Middle calyx & $\mathrm{n}=5(17.20 \%)$ & $\mathrm{n}=0(0.00 \%)$ & $\mathrm{n}=2(16.70 \%)$ & \\
\hline Upper calyx & $\mathrm{n}=1(3.40 \%)$ & $\mathrm{n}=0(0.00 \%)$ & $\mathrm{n}=0(0.00 \%)$ & \\
\hline Pelvis & $\mathrm{n}=7(24.10 \%)$ & $\mathrm{n}=3(50.00 \%)$ & $\mathrm{n}=2(16.70 \%)$ & \\
\hline Stone analysis & & & & 0.540 \\
\hline Calcium oxalate monohydrade & $\mathrm{n}=25(86.20 \%)$ & $\mathrm{n}=5(83.30 \%)$ & $\mathrm{n}=9(75.00 \%)$ & \\
\hline Calcium dihydrade & $\mathrm{n}=4(13.80 \%)$ & $\mathrm{n}=1(16.70 \%)$ & $\mathrm{n}=2(16.70 \%)$ & \\
\hline Postoperative intervention & & & & 0.0001 \\
\hline None & $\mathrm{n}=29(100.00 \%)$ & $\mathrm{n}=3(50.00 \%)$ & $\mathrm{n}=12(100.00 \%)$ & \\
\hline Present & $\mathrm{n}=0(0.00 \%)$ & $\mathrm{n}=3(50.00 \%)$ & $\mathrm{n}=0(0.00 \%)$ & \\
\hline CT control & $\mathrm{n}=29(61.7 \%)$ & $\mathrm{n}=6(12.80 \%)$ & $\mathrm{n}=12(25.5 \%)$ & \\
\hline
\end{tabular}

Table 2. Relation factors with stone-free, residual fragment and CIF

\begin{tabular}{|c|c|c|c|c|}
\hline & Stone-free & Residual fragment & CIF & $\mathrm{p}$ \\
\hline Gender & & & & 0.361 \\
\hline Male & $\mathrm{n}=15(51.70 \%)$ & $\mathrm{n}=5(83.30 \%)$ & $\mathrm{n}=7(58.30 \%)$ & \\
\hline Stone localization & & & & 0.716 \\
\hline Lower calyx & $\mathrm{n}=16(55.20 \%) \mathrm{n}$ & $\mathrm{n}=3(50.00 \%)$ & $\mathrm{n}=8(66.70 \%)$ & \\
\hline Middle calyx & $=5(17.20 \%)$ & $\mathrm{n}=0(0.00 \%)$ & $\mathrm{n}=2(16.70 \%)$ & \\
\hline Pelvis & $\mathrm{n}=7(24.10 \%)$ & $\mathrm{n}=3(50.00 \%)$ & $\mathrm{n}=2(16.70 \%)$ & \\
\hline Postoperative intervention & & & & 0.0001 \\
\hline Absent & $\mathrm{n}=29(100.00 \%)$ & $\mathrm{n}=3(50.00 \%)$ & $\mathrm{n}=12(100.00 \%)$ & \\
\hline Present & $\mathrm{n}=0(0.00 \%)$ & $\mathrm{n}=3(50.00 \%)$ & $\mathrm{n}=0(0.00 \%)$ & \\
\hline
\end{tabular}

Table 3. Relation factors with ston-free, residual fragment and CIF

\begin{tabular}{|c|c|c|c|c|}
\hline & Stone-free & Residual fragment & $\mathrm{CIF}$ & $\mathrm{p}$ \\
\hline Age, year & $51.34 \pm 10.43$ & $49.17 \pm 11.87$ & $52.33 \pm 4.52$ & 0.802 \\
\hline Stone size, $\mathrm{mm}$ & $28.55 \pm 5.62$ & $27.33 \pm 4.46$ & $24.92 \pm 2.75$ & 0.110 \\
\hline Operation time, $\min$ & $57.07 \pm 11.46$ & $59.17 \pm 7.36$ & $54.17 \pm 8.21$ & 0.582 \\
\hline BMI & $25.28 \pm 2.64$ & $27.67 \pm 1.63$ & $26.33 \pm 2.87$ & 0.106 \\
\hline
\end{tabular}


adults treated with PNL. KUB and ultrasound correctly detected 40 and $37 \%$ of fragments detected on CT, respectively. When fragments smaller than $5 \mathrm{~mm}$ were detected on CT, the sensitivity of KUB and ultrasound was decreased to 15 and $31 \%$, respectively [8].

In one of early researches, 80 patients examined by CT, of whom 66 also underwent KUB following PNL. Sensitivity and negative predictive value of postoperative KUB could be calculated from their published data as 58 and $70 \%$, respectively [9]. In another similar study that included 29 patients who underwent PNL, sensitivity and negative predictive value calculated to be 50, 47, 75 and $64 \%$ for KUB and plain tomography for large volume renal calculi respectively [10]. Pearle et al. [6] compared KUB and noncontrast CT against second look nephroscopy in 36 patients and second look nephrosocopy was found to be as gold standard. They found that the sensitivity and negative predictive value of KUB were 46 and $39 \%$, respectively, while those of CT were $100 \%$ for both. But specificity for detected fragment was only $68 \%$ on CT [7].

In our study we calculated specificity $61.7 \%$ for KUB and only $6.3 \%$ of patients required additional procedure. We performed 5-mm section multidetector scanner CT for all patients. Rates of detected CIF and residual fragments on CT are 66.6 and $33.4 \%$ respectively. Raman et al. [10] reported that if residual stones greater than $4 \mathrm{~mm}$, second look flexible neproscopy is a cost advantageous practice and prevents secondary stone events that occur frequently. In contrast, for residual fragments $2 \mathrm{~mm}$ or less second look flexible neproscopy is neither clearly clinically indicated nor cost beneficial [11]. In our study 50 and $0 \%$ of residual fragments and CIF required additional procedure on follow-up respectively. Postoperative imaging had minimal advantage for identifying which patients required any procedure and the need for second procedure. But it has disadvantages like additional cost and exposure of radiation. However fluid intake, salt limitation and symptomatic therapy can potentially alter the natural history of residual fragments and CIF. These regimens reduce the likelihood of future stone events and preventing new stone formation.

The purposes of the study is to determine if rest calculus can be observed during CT and if they cause any clinical problems in the patients whose postoperative KUB and rigid nephroscopic scan indicate stone-free condition. Only CT and digital KUB data were compared for postoperative scans. Determination of the longest caliber in the study is only performing CIF and rest calculus differentiation. Because stones that are smaller than $5 \mathrm{~mm}$ are defined as CIF by EAU guideline, we used $5 \mathrm{~mm}$ incision range in the study.

The purpose of scans after PNL is to determine if additional interference is necessary. Our study was designed to answer the question that are patients, who are accepted as stone-free in postoperative KUB scan, completely stone-free and to have an idea about its clinical significance. The clinical significance of CIF determination is a rather controversial issue that no treatment apart from frequent follow-up is necessary. CIF determination after the operation didn't make any interference necessary during follow-up. But operation was necessary for half of the patients who are determined to have residual fragments in our study.

During postoperative scans, especially CT may give the doctor an idea about follow-up frequency of residual fragment and interference operation. But CT is certainly more expensive and causes more radiation exposure than KUB. The fact that only $6.3 \%$ of the patients needed interference treatment makes the necessity of this method questionable. This indicates the necessity of more frequent follow-up for the patients who had residual fragments.

\section{Conclusion}

Routinely, KUB is used to determine stone-free ratio after PNL but is not sufficient to detect residual calculi and/or CIF at $38.3 \%$ of patients. However we think that CT scan is not absolutely required on follow-up because only $6.3 \%$ of patients had required additional intervention. KUB is cost effective and safe on radio opaque calculi and reduces exposure of radiation on follow-up. 


\section{References}

1 Kim SC, Kuo RL, Lingeman JE: Percutaneous nephrolithotomy: an update. Curr Opin Urol 2003;13:235-241.

-2 Pearle MS, Lingeman JE, Leveillee R, Kuo R, Preminger GM, Nadler RB, Macaluso J, Monga M, Kumar U, Dushinski J, Albala DM, Wolf JS Jr, Assimos D, Fabrizio M, Munch LC, Nakada SY, Auge B, Honey J, Ogan K, Pattaras J, McDougall EM, Averch TD, Turk T, Pietrow P, Watkins S: Prospective randomized trial comparing shock wave lithotripsy and ureteroscopy for lower pole caliceal calculi $1 \mathrm{~cm}$ or less. J Urol 2008;179: S69-73.

3 Haleblian G, Kijvikai K, de la Rosette J, Preminger G: Ureteral stenting and urinary stone management: a systemic review. J Urol 2008;179:424-430.
4 Parsons JK, Lancini V, Shetye K, Regan F, Potter SR, Jarrett TW: Urinary stone size: comparison of abdominal plain radiography and noncontrast CT measurements. J Endourol 2003;17:725-728.

5 Levine JA, Neitlich J, Verga M, Dalrymple $\mathrm{N}$, Smith RC: Ureteral calculi in patients with flank pain: correlation of plain radiography with unenhanced helical CT. Radiology 1997;204:27-31.

6 6 Pearle MS, Watamull LM, Mullican MA: Sensitivity of noncontrast helical computerized tomography and plain film radiography compared to flexible nephroscopy for detecting residual fragments after percutaneous nephrostolithotomy. J Urol 1999;162:23-26.
7 Osman Y, El-Tabey N, Refai H, Elnahas A, Shoma A, Eraky I, Kenawy M, El-Kapany H: Detection of residual stones after percutaneous nephrolithotomy: role of nonenhanced spiral computerized tomography. J Urol 2008;179:198-200.

8 Geterud K, Henriksson C, Pettersson S, Zachrisson BF: Computed tomography after percutaneous renal stone extraction. Acta Radiol 1987;28:55-58.

$\checkmark 9$ Denstedt JD, Clayman RV, Picus DD: Comparison of endoscopic and radiological residual fragment rate following percutaneous nephrolithotripsy. J Urol 1991;145:703-705.

10 Raman JD, Bagrodia A, Bensalah K, Pearle MS, Lotan Y: Residual fragments after percutaneous nephrolithotomy: cost comparison of immediate second look flexible nephroscopy versus expectant management. J Urol 2010;183:188-193. 